\title{
Makeover Culture’s Dark Side: Breasts, Death and Lolo Ferrari
}

\begin{abstract}
The word 'makeover' is dotted through popular culture and is applied to a range of activities including home renovation, gardening, urban renewal, and business invigoration. Makeover culture is part of a socio-cultural paradigm that values endless improving, renovating and rejuvenating. Makeover citizens enact urgent and neverending renovations of the self. Cosmetic surgery is both symptom and manufacturer of makeover culture. It is indicative and constitutive of an arena in which ideal objects and subjects are always being improved, and in which everything - including the body - is always ripe for enhancement.
\end{abstract}

This paper focuses on the 1990s French pornography star, Lolo Ferrari. Two aspects of Ferrari’s famous cosmetic surgery are examined. They indicate a darker side of makeover culture - one that is less about lifestyle and surface gloss and more about pornography, death and unconsciousness. The first is her breasts, which I examine in relation to gigantism and normalised notions of femininity, and as symbols of the transition from girl to woman. The second is Ferrari's striking declaration that she loved being under anaesthetic. I delve into this notion to discuss how immobility, stasis, decay and mortality are crucial parts of makeover culture's promises of transformation. 


\section{Introduction}

Because I could not stop for Death-

He kindly stopped for me-

The Carriage held but just Ourselves-

And Immortality

(Emily Dickinson, 1890).

Lolo Ferrari was in Cyprus before we got her... she'd had so many hands on her that there was a hole between her breasts - so we had to fix her

(A curator describing the Lolo Ferrari waxwork on display at the Checkpoint Charlie Museum in Berlin, Reuters, 2005).

Born Eve Valois, Ferrari changed her name to Lolo, which is French slang for breasts and mother’s milk (Greer, 2000). She was famous for her appearances on the BBC late night show Eurotrash where her pithy and risqué soundbites accompanied the spectacle of her massively augmented breasts. Her chosen bodily configurations were of extreme proportions: after between eighteen and twenty-five cosmetic surgery operations (reports vary), most of them to enlarge her breasts, Ferrari became literally mythic, resembling an ancient fertility goddess or the graffiti project of a horny adolescent. Her breast implants were the biggest in the world and are cited in the 1999 Guinness Book of World Records. Ferrari died early in 2000 at the age of thirty or thirty-eight (again, reports vary) of what was first reported as an overdose of prescription anti-depressants. Her husband and 
manager, Eric Vigne, was later arrested and charged with her murder by suffocation but the charges were subsequently dropped (Henley, 2002; 2002a). Whether she suicided or was murdered Ferrari is a full-blown tragic figure: the Marilyn Monroe or Kurt Cobain of a world at the nexus of celebrity, cosmetic surgery, and pornography. Her final photos show breasts the size and shape of soccerballs: the great silicone sacs had distorted the skin on her petite frame and it had become dark and inflamed, riddled with stretch marks. Her aureoles were the size of her palms. One of the many myths around Ferrari is that like ‘Elephant Man’ John Merrick she had trouble sleeping because of her unusual body. Whether true of not, she was probably in serious muscular and dermatological pain.

There is a compellingly kitsch poetry about Ferrari’s life. She was utterly self-aware, self-destructive, funny and melodramatic. She occasionally displayed biting insight into her own created self: 'I'm like a transvestite... I've created a femininity that's completely artificial... I hate reality — I want to be wholly artificial' (http://www.goodbyemag). Her ability to poetically self-analyse and her philosophical depth make cultural analyses of her life quite gripping. She embodied many contradictions: victim and successful businesswoman, little girl lost, exploiter and manufacturer of her own assets. Ferrari carried her staged femininity like a shield but also like a weapon of self-annihilation, eventually making it, literally, so heavy that it became unbearable.

That shit isn't natural either. They could've recycled all the plastic in this bitches chest and made a few bumpers for a couple SUV's... Lolo Ferrari, who was billed as 'the woman with the biggest breasts in the world' and had a reputed 71-inch 
$(177.5 \mathrm{~cm})$ silicone-enhanced bust and was as ugly as her tits were big. As soon as they rule out that one of those tits of hers didn't get a mind of its own and roll up on her face in her sleep, I think they might have a case against the husband (http://www.8bm.com/diatribes/volume01/036/727.htm).

The above quote, taken from Nkrumah Shabazz Steward's popular web log, is a florid and hateful yet typical example of common attitudes towards Ferrari. Vilification is standard in writing about her while mockery and misogyny abound. Most myths connect her breasts to her death:

- she died in surgery;

- one of the implants burst and her breast became gangrenous;

- both implants burst on an aeroplane because of cabin pressure;

- the weight of them suffocated her by pressing on her lungs, or

- (Steward's novel variant quoted above) they rolled up and smothered her.

Such rhetoric often suggests that having transgressed so many boundaries she deserved death-by-breast. For many, the breasts coming 'alive’ and killing her is an apt ending to her story.

\section{Lolo’s Breasts, Our Breasts (*)(*)1}

${ }^{1}\left(^{*}\right)(*)$ is sometimes used to represent Ferrari by her fans on websites. 
Breasts are layered with cultural and social anxieties. They represent both maternity and eroticism, aspects of womanhood that western culture almost obsessively disjoins. Phenomenologist Iris Marion Young identifies the patriarchal dependence on a division between motherhood and sexuality as 'one of the most overdetermined dichotomies in our culture' (1992: 198) and finds that conflicting expectations around mothering and sexuality coalesce in the breast. Woman's 'life experience' and her 'breasted experience' are always linked, because breasts are 'in question in this society, up for judgement... and [woman] has not escaped the condition of being problematic’ (1990: 198). But Young also suggests that breasts are resistant because in embodying conflicting discourses they complicate borders (1990: 199). Similarly, semiotician Gillian Fuller notes their capacity to break through boundaries:

...breasts rupture the stability of the categories they are meant to delimit: in one imagining the breast is cloaked, covered by the head of a suckling child, in another it is revealed and fully fetishised in magazines like Hooters and Big Ones (Fuller, 1997).

Breasts must also be contextualised within the most pervasive and normalising set of disciplines upon which contemporary heterosexual women's bodies are shaped: the tyranny of slenderness (Bordo, 1993; Chernin, 1994; Hesse-Biber; 1996). However dutifully we diet for weight loss and labour in gyms to 'make something' of our bodies, our breasts remain recalcitrant. They aren’t 'improved’ or even very much changed through exercise or starvation. The only way to 'make something' of breasts is through 
surgery. ${ }^{2}$ Thin, athletic bodies with defined abdominal muscles but little mammary tissue feature in almost all 'before/after’ sequences on cosmetic surgery websites. Cosmetic surgery allows the thin body to regain 'femininity' (curves) without getting fat. This is not to say that the only women who have implants are those who are thin and muscular, but rather that the ideal feminine body is based around firm flatness that can be further ‘improved’ with selected augmentations. Dieting and gym work create ideal feminine bodies that are thin, upright and hard - in other words phallic. In turn, breasts become a most problematic region of the female anatomy because they define the body as that of a woman whilst simultaneously detracting from its phallic quality. Jon Stratton suggests that while large breasts don’t strictly 'fit' into a phallic ideal they are aesthetically and culturally necessary because they reassure the man that the 'male' (phallicised) body he sees before him is in fact female:

... as a consequence of cultural fetishism, men want women both to have breasts and to have no breasts, which is further compounded because the process of reducing body size to fit phallic ideals reduces breast size. One reason for the attraction of breast augmentation surgery is that with it a woman can have a phallic body with clearly emphasised breasts (Stratton, 1996: 161).

\footnotetext{
2 This cultural paradox is exemplified and the whole tension between 'hardbodies' and breasts is intensified in bodybuilding culture. The bodybuilding arena is perhaps the site in Western culture where women's bodies are seen to be the most masculine, particularly during competition where bodies must display maximum muscle and minimum fat/softness. In bodybuilding, breast implants are almost standard. Nearly a decade ago at least eighty percent of A-grade competitive women body builders in the US had breast implants, and all women featured on the coveted cover of Flex had implants (Heywood, 1998: 35-36).
} 
In the late $20^{\text {th }}$ Century healthy breasts became medicalised according to their appearance: women with small or big breasts were labelled 'hypomastic' or 'macromastic' respectively while women whose breasts had sagged because of age or breastfeeding were suffering from 'ptosis'. As cosmetic surgery gained momentum all sorts of breasts became ripe for fixing (Haiken, 1997; Gilman, 1999). Historically, cosmetic surgery, misogynistic culture and medicine have been intertwined in the ‘discovery’ of both diseases and cures (Fraser, 2003a; Jacobson, 2000; Zimmerman, 1998). Now, in makeover culture, consumer and medical cultures are merging, perhaps most strikingly through cosmetic surgery. At the time of writing, breast augmentation is the most popular cosmetic surgical procedure in the UK, and the most popular after liposuction in the US. ${ }^{3}$ In makeover culture women who have aesthetic breast surgery tend to see themselves as consumers rather than patients, as shoppers rather than as 'sick', and the medicalisation of healthy breasts seems to be slipping into the background. In its place is emerging the 'surgical breast' that happily declares itself to the world. Women shop around for surgeons, wear new breasts like fashion items and make no pretence of them being 'natural'. I suggest that the purpose of breast implants in makeover culture is, more than anything else, the implants themselves. As Marianne Guarena, author and star of the website 'YES THEY'RE FAKE!' writes:

I am thrilled to finally be getting my new boobs!! I am so excited I feel as though I am on a high. I have always wanted fake-looking, round boobies and here I am

\footnotetext{
${ }^{3}$ American Society for Aesthetic Surgery (http://www.surgery.org/press/procedurefacts-asqf.php); British Association of Aesthetic Plastic Surgeons (http://www.baaps.org.uk/);
} 
about to get me some, not to mention get my fat sucked out and put in my face! lol! (www.yestheyrefake.net)

One of makeover culture's aesthetic values is based on artificiality as an end in itself, where the clearly manufactured and purchased is prized over an organic or 'natural' look. An interviewee ${ }^{4}$ described her new breast implants to me over the telephone:

Oh, I wouldn’t say they look a hundred percent natural... they’re quite spaced, separated. And now, I mean, it’s like coz I've lost that four kilos I'm too skinny to have such big breasts. And they're up high and real perky, there’s no sag. They look more sexy than natural ones! [laughing].

The new desirability of the 'non-natural' is commented on by Deborah Covino: 'the ideal body is [now] an aesthetic image, conceived and presented as or in a medium other than flesh' (2004: 4, my italics). Using this logic the less ‘fleshy' and more ‘plastic' (i.e. large in proportion to frame, high and taut) breasts appear the more sought-after they are.

So implants 'tame' the phallic female body, bringing it back into line as primarily gendered feminine. They are also increasingly valued as consumer 'display' items. But they do not automatically bestow acceptable femininity. Many popular women's magazines, especially those that feature stories on 'Cosmetic Surgery Disasters!' show that surgical breasts may create dissonances and engender hatreds by being 'wrongly'

${ }^{4}$ In 2003 and 2004 I conducted interviews with sixteen cosmetic surgery recipients. They all lived and worked along the Eastern seaboard of Australia, mostly in Sydney but also in Melbourne, Brisbane, and on Queensland's Sunshine Coast. 
shaped, scarred, lopsided, naked, on display or - most commonly - simply too big. The 'too big' implant indiscretion is perhaps the most visible one and therefore the most demonised in popular media. Ferrari shares this category with women like Jordan, an English page-three model and star of British Celebrity Survivor, and (the also deceased) Anna Nicole Smith, a U.S. playboy model famous for marrying a geriatric billionaire. These B-grade celebrities are gigantically feminine - they overcompensate for being phallic. But while Smith and Jordan perhaps unwittingly misread the aesthetic and cultural rules they sought to assimilate, Ferrari was quite aware of the borders she was transgressing. In this way Ferrari's breasts are feminist: they break down barriers, they consciously push the feminine body beyond its patriarchal casings. Fuller describes Ferrari as a 'feminist bad girl' whose high, tightly encased, upright breasts are the embodiment of a 'hyper femininity' that both subverts and critiques '...the braless, freeswinging and ultimately maternal breast of the 70s feminist good girl' (1997). Perhaps upholding Ferrari as an embodiment of third wave feminism is stretching my point but she certainly enacts a form of femininity that is overtly subversive as well as complicit, that makes a running and ironic commentary on itself, and that highlights many of the complex contradictions around breasts in makeover culture.

\section{Lolo's Enchanted Slumbers}

After surgery, you lie in bed waiting for your day. Instead of obscuring your face, the bandages seem more like a blank field of possibility - of the beauty promised, of the happy ending to the surgical story (Blum, 2003: 11). 
Lolo Ferrari takes the notion expressed in this quote a step further, declaring: 'I adore being operated on... I love the feeling of a general anaesthetic - falling into a black hole and knowing I'm being altered as I sleep' (http://www.goodbyemag). Purporting to love the experience of the actual anaesthetic is something I have not found expressed elsewhere in the cosmetic surgery world. Ferrari's strongly stated satisfaction with unconsciousness is unseemly and unacceptable, perhaps on a par, in terms of bad taste, with her pornographic movie roles. Like the stereotypical promiscuous woman who seeks out sex and enjoys it too much, Ferrari is too vocal about her taste for oblivion. In a culture where self-control, self-determination and self-awareness are paramount the notion of willingly surrendering to an anaesthetic is something abhorrent, something definitely not meant to be pleasurable, but perhaps something also deeply seductive. Unconsciousness leading to transformation is not new. In fact, the idea of being comatose while allowing others to take responsibility for your fate and then waking up as a different person has strong roots in myth. I show in this section how fairytales like The Sleeping Beauty and Snow White and the Seven Dwarves can be used as portals into an understanding of Ferrari's actions within makeover culture and into some of the mythical promises of cosmetic surgery in general. In these stories the supreme beauty of the sleeping, or dead, princesses is dwelt upon - their immobility is part of their desirability. Thus, the chief fascination in the fairytales is not in the curses or in the happy endings but in the poison-induced living embalmment of their heroines. 
In The Sleeping Beauty, newborn princess Briar-rose is cursed by a vengeful old fairy (wicked mother figures in fairytales are almost always old, and therefore depraved). The curse means that the princess will die on her fifteenth birthday, but her fate is lessened by a good (and young and beautiful) fairy. The good fairy is not strong enough to completely counteract the revengeful fairy's curse, so the remedy to death here is stasis. Hence at age fifteen, instead of dying, Briar-rose sleeps for a hundred years, along with everyone in her castle. The century passes, a prince wakes her with a kiss, and they live happily ever after. An analysis of the 'between-time', the hundred years of sleep, helps to explain the importance of anaesthesia in makeover culture. Mythographer Marina Warner notes that periods of limbo are commonly interpreted in academic literature as a 'slow incubation of selfhood... [and] eventual sexual fulfillment' (1994: 219-29). But Warner herself prefers to see them as symbols of the 'dark times' that can follow the first encounter between an older woman and her new daughter-in-law. The combination of these two readings suggests that such sleeps are a fantastical way to bypass uncomfortable, messy, transformative teenage and early-adult years. We simply fall asleep as pre-teens and wake up as fully-fledged adults with heroic, adoring husbands and our difficult mothers and mothers-in-law out of the way. This mythology is directly applicable to makeover culture, which incorporates this promise of mythical transformation while sleeping. The notion of magical transformation during cosmetic surgery is common. Many of the cosmetic surgery recipients I interviewed expressed wonder when describing their awakenings. One told me: 
Oh definitely, I was so excited, at the prospect of being a new person, and I know when I woke up and you know I looked down and could see these breasts looking up at me and you know they were strapped [up]... and I thought it was hilarious to be quite honest that I had these breasts that you could actually see, sitting up in front of you. But from the very first day I was just so thrilled with them, really.

In Snow White and the Seven Dwarves, Snow White, like Briar-rose, is immobilised by a wicked mother figure. Her stepmother gives her a poisoned apple. Snow White 'dies' but her body doesn’t decay: ‘.. she still looked as fresh as though she were alive, and still had her beautiful red cheeks' (Grimm, 1973: 269). Like Briar-rose she is in a state of suspended animation: neither dead nor alive, not breathing yet 'fresh'. These sleepdeaths are quarantine stations where the girls stay out their transitions into adulthood, making the move from helpless children to powerful women (both become queens) appear effortless.

Ferrari's narrative also features an evil mother, whom she told reporters was hateful, overbearing and castigating:

My mother told me I was ugly and stupid... She said I was only good for emptying chamber pots. I wanted to be an anaesthetist, but you can't learn with a mother like that. Actually, I'm like my mother. She thinks she's ugly too. When I was born, it was herself that she saw and she stuck all sorts of negative stuff on me. She did all she could to stop me living. My mother was always very unhappy 
with my father. My father was this macho guy who was never there and deceived her openly. So she revenged herself on me. She told me I was revolting too, that no one would ever want me. She hit me sometimes with a riding crop. I was frightened and I was ashamed; I wanted to change my face, my body, to transform myself. I wanted to die, really (quoted in Henley, 2000).

She describes a horribly tragic real-life fairytale scenario, right down to the Cinderellastyle chamber pots. In adulthood Ferrari endeavoured to make other aspects of her own life magical: her house in the south of France had a white picket fence and a pink interior, she favoured princessy outfits complete with tiaras, and even wore her own ironic version of the white lacy bridal gown. Others have picked up on the fairy story aspects of her life including Marie Claire journalist Elisabeth Alexandre:

She was really very touching. You wanted to imagine her in a dream world with a big, airy house and white bunny rabbits and pink butterflies and friends who would like her truly for what she was, not for the money they could make out of her. The reality was very different (quoted in Henley, 2000).

Another parallel is with the state induced by anaesthetic. It is in line with the poisonproduced deathlike sleeps that Snow White and Briar-rose experience. Anaesthetic was Ferrari's 'curse', the poisoned instrument by which she would 'die' and yet awaken magically transformed, having escaped her evil mother and become beautiful. Importantly, her deep embrace of anaesthesia (perhaps connected to her thwarted dream 
to be an anaesthetist herself) is not a strange sickness confined to a single individual. It is rather a slight twist on the everyday cultural logics of makeover culture, which valorise endless transformation into something better. For example, Extreme Makeover, a nowdefunct U.S. television program in which people underwent multiple cosmetic surgeries, promised a ‘truly Cinderella-type experience’ (Extreme Makeover official website (n.d.)). Ferrari spent her whole adult life having cosmetic surgery operations or working towards them, effectively cancelling out an ordinary transition into womanhood. And, when she wasn't actually in the 'black hole' of anaesthetics that she loved so much, she created a perpetual twilight for herself with prescription sedatives (Henley, 2000).

Contemporary gender studies teaches how implants 'tame' the phallic female body, bringing it back into line as primarily gendered feminine. Ancient fairytales teach that periods of magical slumber transform persecuted girls into desirable women, 'domesticating' them but also making them powerful. Ferrari combines these two narratives: she embodies an extreme of 'implantedness' whilst simultaneously displaying the bizarre logical outcome of a culture where the many 'little deaths' of anaesthetic lead to the illusion of immortal loveliness.

\section{What a Lovely Corpse}

Anaesthesia, fatal if not administered properly, is a temporary 'death'. In this section and in the next I compare Ferrari’s immobilised anaesthetised states to her role as an implanted pornographic sight. I theorise that her anaesthetics were 'first burials' - 
mythic actions crucial to the perpetuation of makeover culture. For literature scholar Elisabeth Bronfen, Snow White’s transparent coffin ‘elicits an aesthetic viewing' (1992: 102). In it she becomes an art object - the dwarves even write her name in golden letters on its side - subjected to the gaze and separated from time and space. Importantly, the prince does not love her before she 'dies': Bronfen asserts that, in the tale, it is only once the fluid feminine body is cleansed, purified, immobile and available for the uninterrupted gaze - in other words only once it is an art work - that it becomes hugely desirable. The prince’s erotic desire is only at the level of viewing: Snow White's still, undemanding body is connected with pleasure and with possession in much the same way that achieving gratification from looking at pornography is connected to purchase or ownership of the erotic image. Bronfen continues: ‘... Snow White performs the apotheosis of one of the central positions ascribed to Woman in western culture; namely that the 'surveyed' feminine body is meant to confirm the power of the masculine gaze' (1992: 102). The figure of the immobilised 'dead' woman on display depicts both female sexuality and death, which are ‘...the two enigmas of western culture...' (1992: 99) ${ }^{5}$. When bodies like Snow White's are inert and exhibited, both death and female sexuality are contained and controlled so that the threat that they present to the living, masculine subject is diminished. Such representations render the '...mutable, dangerously fluid, destabilised feminine body... cleansed, purified, immobile’ (Bronfen, 1992: 99). Ferrari's body takes on the form of an artwork via the same mechanisms. She is rendered

${ }^{5}$ Bronfen analyses many representations of feminine death including the anatomical wax casts of cadavers - mainly women - that were popular in the eighteenth century. She also looks at Richardson's 1747 novel Clarissa wherein a man wishes to embalm the heroine's corpse, remove her heart and keep it in spirits so he can look at it forever. 
inert by her anaesthetics and becomes an aesthetic object ${ }^{6}$ - whose primary function is to be looked at sexually - because of her breasts. Her breasts, the products of her moments of immobilisation, are also a permanent disavowal of the 'mutable, dangerously fluid' woman's body that Bronfen describes. Bronfen goes on to deploy Freud's theory of scopophilia - where he asserts that there are two linked categories of desire, visual and tactile - to theorise the attraction of the 'dead' beauty.

The 'embalmed corpse' satisfies as an object of sight and alleviates the viewer of any need to progress to the 'normal sexual aim'. Death sanctions what would otherwise, for Freud, be a perversion - the exclusive privilege of the gaze as it becomes, supplants, and excludes the sexual activity connected with touching the other (Bronfen, 1992: 102).

For Freud, healthy visual desire naturally leads to tactile desire. In other words, enjoyment in seeing progresses to a desire to touch what we see. In the figure of the permanently sleeping beautiful woman, or the embalmed corpse, these two categories of desire are collapsed: there is visual desire, but the desire to touch is not acceptable, or cannot be fulfilled. Further, when death is connected in this way to the inaccessible - to that which is untouchable - death itself also becomes remote and therefore unthreatening, completely other. It cannot touch the viewer: ' ....any image of death contains as one of its signifiers the observer's survival' (Bronfen, 1992: 102). I suggest that the anaesthetised, augmented, pornographic Lolo Ferrari is just such an image of death:

\footnotetext{
${ }^{6}$ Anaesthetic and aesthetic have the same etymological root, the Greek aesthēsia, meaning perceptive or sensible.
} 
completely visually available but untouchable. Pornography, especially pornography that represents hyper-feminine pneumatic bodies like Ferrari’s, obfuscates the possibility of touching. The link is strong between Lolo Ferrari and those immobilised feminine bodies that Bronfen asserts conflate desire and tactility. Ferrari’s anaesthetics, her pornographic image, and her specific body modifications are vivid manifestations, both literal and metaphoric, of this parallel.

Ferrari's breast implants are uncontained by the usual temporal and spatial boundaries to which mammaries are subject. As a pornography star she is available, indefinitely and forever, to a sustained gaze that parallels the unreturned gaze that Snow White receives while she is incapacitated ${ }^{7}$. Perhaps her statements about loving anaesthetics are implicit recognition of this linkage; they may also be a way of re-claiming and subverting the gaze. She actively becomes passive (a contradiction-in-terms similar to 'passive aggression') and thus gives voice to the silent, immobilised figure of perfect femininity. Passivity need not be all negative: submission and surrender can be active and chosen. Susan Bordo points out, in a discussion about the trend towards 'soft' portrayal of male bodies in advertising campaigns, that the act of offering oneself is in fact far from passive: “ “passive” hardly describes what's going on when one person offers himself or herself to another. Inviting, receiving, responding - these are active behaviours... It's a macho bias to view the only real activity as that which takes, invades, aggresses' (Bordo, 2000: 133). Using this logic, undergoing cosmetic surgery may be a forceful rather than a passive act.

\footnotetext{
${ }^{7}$ Many pornographic websites still include pictures of Ferrari and make no mention of her death.
} 
Passivity is a complex term in relation to cosmetic surgery. In some popular media and in all cosmetic surgery advertising women who don't have cosmetic surgery are negatively construed as 'passive’: they have foolishly accepted their less-than-desirable lot despite the surgical 'options' available. On the other hand, feminist discourse around cosmetic surgery often portrays women as negatively 'passive' if they do have cosmetic surgery: they have given in to repressive beauty ideals and failed to love themselves 'naturally' (Fraser, 2003). Ferrari seemed to inhabit a space apart from these two poles of passivity. She didn’t embrace a normative beauty and nor did she 'accept' her 'natural' body. Rather than using cosmetic surgery to fix a 'deformity' or to 'amend the abject body’ so it might become part of a clean and smooth community of similar individuals (Covino, 2004), Ferrari forcefully and continually re-designed herself as a singular caricature for the male gaze. She did this in such a confronting way that it cannot be interpreted as mere conformity: it is a wilful, active, and even aggressive embrace of certain passive stereotypes.

\section{First and Second Burials}

Finally, Bronfen uses the work of religious anthropologist Robert Hertz to describe how bodies like Snow White's - immobile, indestructible, 'art' works - cannot be sustained. Hertz examined societies that practiced primary and secondary burial rites, and asserted that in these rituals death was not a singular event but rather a progression. Total separation between the world of the living and the world of the dead only happened after 
corpses and mourners had gone through a series of ‘between’ stages. He described the double death rites of the Olo Ngaju people of Borneo (MacDonald, 1999) where two burials - one 'temporary' and one 'final' - occur before death is fully accepted. During the first burial period the dead person is considered to be neither in this world nor in another but rather in-between, occupying a role of doubleness. The doubleness, necessary but problematic, is then ended with the enactment of a second burial, after which the spirit of the deceased is definitively sent to the other world. Bronfen suggests that while it is in the first burial's transition stage the corpse represents a temporary triumph over death as well as a kind of immortality - it is dead and alive. But she asserts that, eventually and inevitably, 'this dangerous though fascinating interzone must cease' (1992: 104). Put simply, the living cannot sustainably cohabit with the dead. The corpse-object of the first burial works as a portal between worlds but this portal cannot remain open permanently. Bronfen argues that in the first burial the corpse is a fetish that makes desire merely optical, rendering death visible but untouchable. However, the reassurance that this provides is dangerous in the long-term because ultimately the corpse represents nothingness: it no longer has a living referent. 'Second burial' then puts it finally to rest, severing its connection to the living world and replacing it with monuments that may resemble the deceased but are definitively representational.

Contained and everlasting bodies like Snow White's in the coffin and Ferrari's in its pornographic frames and its anaesthetised states deny the mutability of the feminine body and also deny death itself. For Bronfen, they stave off temporality and work to reassure the viewer that he is both masculine and alive. It is not only the object of the gaze but 
also the gazer who is outside of temporality, and this must also come to an end: staving off time is eventually an act that cannot be sustained. She notes how representations of and narratives about dead feminine bodies all eventually require closure in the form of reanimation or decomposition. This closure is the 'second burial'.

Second burial need not be literal. In Western culture, where the dead disappear rapidly and the 'transit passage' between life and death is hidden or denied, this is particularly the case. We rarely have the opportunity to view or touch real dead bodies: many people's first and last contact with the deceased is via a closed coffin. Our 'first burials' come in the form of representations of death. Baudrillard says that many of our cultural forms are deathlike and writes about Californian houses (although this quote could equally be attributed to cosmetically altered bodies):

All dwellings have something of the grave about them, but here the fake serenity is complete. The unspeakable house plants, lurking everywhere like the obsessive fear of death, the picture windows looking like Snow White's glass coffin, the clumps of pale, dwarf flowers stretched out in patches like sclerosis, the proliferation of technical gadgetry inside the house, beneath it, around it, like drips in an intensive care ward, the TV, stereo, the video which provide communication with the beyond... (1998: 30).

The surgically enhanced body also has a 'fake serenity' because all its signs of age, wear and tear have been stretched out. While cosmetic surgery can be read as fear of mortality 
and disgust with corporeality, it is also precisely the opposite. It involves the killing of a living human part (skin, muscle), and the replacement of the live with the dead (an implant). Efrat Tseëlon notes the similarities between the processes of preparing a body for mummification and preparing a body for cosmetic surgery. They both cut into and thus damage the skin of the body in order to - paradoxically - preserve that very surface: 'the aesthetisation of death and the beautification of the living are defensive strategies. They are designed to protect the person from realisation of some lack by creating an illusion of wholeness and immortality' (Tseëlon, 1995: 117).

Makeover culture's 'finished products' are the unlived-in spaces shown in ironically named 'lifestyle' magazines - the perfectly tszujed ${ }^{8}$ interiors with throw cushions placed just-so. These ‘still lives’ are also ‘living deaths’, as are still pornography images, especially those that feature plasticated 'living dolls' like Ferrari. The messy stages of makeover culture then, the stages of renovation and surgery where nothing is contained, lead up to ideal deathlike images, where everything is finalised and static.

Snow White in her coffin and Briar-rose in her thorned castle are symbolic first burials. Ferrari enacted her own first burials - as perhaps all cosmetic surgery recipients do to a lesser degree - in the form of multiple, much-loved anaesthetics. She was always flirting with the idea of being a fetish, an embalmed, non-fluid, immobile and hyper-feminine representation of death to be gazed upon. Perhaps stuck in the groove of a continual

\footnotetext{
8 'Tszuj' is a word popularised by the television show Queer Eye for the Straight Guy. It means '...taking something and tweaking it, fluffing it, nudging it or finessing it to be a little more fabulous and a lot more fun' (Allen, Douglas, Filicia, Kressley, Rodriguez, 2004: 9). In the case of interior decorating it might mean adding a 'final touch' like a scented candle, in fashion it might mean a stylish rolling of the sleeves or addition of a scarf.
} 
stream of first burials, and given that first burial is ultimately incomplete and untenable, Ferrari had to die young. Her 'second burial' was her actual death. In fairy stories, the second burial is usually performed as a kind of rebirth, but Bronfen suggests that Snow White's reanimation can be seen as a kind of sacrifice - 'a sacrifice of the haunting fetish, the double' (1992: 104) - that which is dead and not-dead. And like all symbolic sacrifices, this one serves to preserve the culture from which it comes. Makeover culture creates and re-creates bodies that are dead and not-dead, that are, like Ferrari's, hard and implanted, metaphorically dead and alive at the same time. So makeover culture too must have its sacrifices, its martyrs for the cause. The 'sacrifices' of makeover culture's extreme practitioners like Ferrari are necessary for the continuing health of the culture. Like the preserved corpse, Ferrari was not sustainable. Snow White and Ferrari both finally return to a state that relies on temporality, a state of mutability. In this way Ferrari is makeover culture’s biggest fan but also its most infamous martyr.

Susan Stewart writes in On Longing (1993) that fantastic gigantic body parts are symbolic environments-in-themselves, engulfing their surroundings as well as their bearers: 'what often happens in the depiction of the gigantic is a severing of the synecdoche from its referent, or whole’ (1993: 89). For example, she shows how the enormous and consuming breasts depicted in Gulliver's Travels swallow up their world and their narrator. A strong sense of engulfment comes about via the position of the observer: 
[with gigantism] the partial vision of the observer prohibits closure of the object. Our impulse is to create an environment for the miniature, but such an environment is impossible for the gigantic: instead the gigantic becomes our environment, swallowing us as nature or history swallows us (1993: 89).

Images of Ferrari, no matter what angle they're taken from, are dominated by her gigantic breasts. In this way they are unlike most heterosexual pornographic images, which centralise the vulva or anus, emphasising woman's receptivity. Out of scale with her tiny body the breasts threaten to engulf the viewer and have indeed already engulfed Ferrari, who is their environment: they are huge blots on the landscape of her body. She initially 'ingested' them by buying them and taking them in, but they then metaphorically swallowed her to the extent that they are her. The gigantic is without containment: combined with the synecdochical over-signification of the part this is what makes Ferrari's breasts overwhelming, anti-receptive, and active. They present a visual 'opposite' to the standard pornographic body, which is open-holed and spreadeagled. This is a positive way to view the giant implants; a less hopeful analysis is that the breasts themselves became fetishist symbols of the all-powerful, threatening mother figure who dominates her daughter's life as described in many fairy stories. In this reading Ferrari gains freedom from the tyranny of the mother only by replacing it with the mightiness of her own ever-expanding mammaries. In a 'real' fairytale the transformations that she underwent while under anaesthetic would have freed her from the wicked and controlling mother or stepmother. But her breast implants created a new 'bad' mother, one that through gigantism became environmentally and historically 
overwhelming. Ultimately - and predictably - Ferrari’s transformations had the opposite effect in her life to those of Snow White and Briar-rose, serving only to replicate the condition she had designed to escape, and setting up an alternative oppression.

\section{Conclusion}

Lolo Ferrari overplayed makeover culture, enacting it in a perverse, perhaps inverse way. She worked and played with cosmetic surgery on literal and mythological levels. Her deliberate agency in inflating the mask of femininity functioned simultaneously to embrace and reject it. Her embodiments of makeover culture’s values were as much about highlighting the death that it aims to circumvent as avoiding it. Importantly, through Ferrari we can see that makeover culture is as much about designing death as it is about designing life.

The suspensions experienced by Snow White, Briar-rose and by Lolo Ferrari via poison and/or anaesthesia are clearly extended moments where transformation can happen without pain. When used as portals into an analysis of cosmetic surgery, they point to the beginnings of a new understanding of it in relation to temporality, namely its complex relation with death and notions of immortality. When makeover culture is 'correctly' performed it embodies elasticity, adaptability, and mobility in physical, mental and emotional terms. And it values, above all, a state of constant becoming. Makeover culture, for all its endless construction of newly finished surfaces, also always creates sites that are in disarray: the dusty 'ruins' of renovations-in-progress, the chaos of 
redecorating, and the bloody, bruised mess of the body in surgery and in recovery. These are all ‘little deaths', foreshadowing and 'doubling' for death even as they facilitate makeover culture. The plaster- and debris-strewn renovation-in-progress looks like a fatally bombed house. Similarly the anaesthetised and bruised cosmetic surgery recipient looks like a near-dead car crash victim. These are reminders that cosmetic surgery and makeover culture are still subject to death and finality, and that in fact it is these inevitabilities that they work in connection with.

An analysis of cosmetic surgery as an anti-ageing technology that works against death and towards a fantasy of immortality could easily slip into utter condemnation of the practice as being ultimately absurd. However, in acknowledging that cosmetic surgery within makeover culture involves embracing deathly moments, and that these suspensions-in-time are part of the life of makeover culture at work, feminists and other scholars are better placed to understand how makeover culture works at deep mythical and symbolic levels. Cosmetic surgery seen through this lens is a new manifestation of an ancient set of symbols about femininity, suffering, transformation and death. This seems to have been something of which Ferrari had an intuitive understanding.

Her eventual real death was no surprise. She said in a late interview, 'All this stuff has been because I can't stand life’ (http://www.goodbyemag). Like a dead infant, she was buried with her favourite teddy bear, in a white casket that she had chosen herself a few weeks before dying. Perhaps finally in death she managed to prolong forever the delicious 'black hole' she had sought so many times via anaesthetic. 
I am grateful to Zoë Sofoulis and Cressida Heyes for our wonderful conversations about the ideas set down here. Thanks are also due to Julie Doyle, Katrina Roen and the two anonymous reviewers who were so generous with their thoughts and suggestions for this piece.

Meredith Jones teaches Digital Media and Cultural Studies at the University of Technology, Sydney. Her first book, Skintight: An Anatomy of Cosmetic Surgery, will be published by Berg, Oxford, in 2008. 
Bibliography

Allen, T., Douglas, K., Filicia, T., Kressley, C., \& Rodriguez, J. (2004) Queer Eye For The Straight Guy, Bantam, Sydney, Auckland, Toronto, New York, London American Society for Aesthetic Surgery http://www.surgery.org/press/procedurefactsasqf.php accessed July 20, 2006

Australian Cosmetic Surgery Advisory Centre http://www.csac.com.au/ accessed 27 August 2005

Awful Plastic Surgery: the good, bad, and ugly of celebrity plastic surgery http://www.awfulplasticsurgery.com/ accessed July 20, 2006 Baudrillard, J. (1998) America, (Trans. Turner, C.) Verso, London \& New York Blum, V. (2003) Flesh Wounds: The Culture of Cosmetic Surgery, University of California Press, Berkeley, Los Angeles, London

Bordo, S. (1993) Unbearable Weight: Feminism, Western Culture, and the Body, University of California Press, Los Angeles

------ (2000) ‘Beauty (Re)Discovers the Male Body’, Beauty Matters (Ed. Brand, P.Z.) Indiana University Press, Bloomington \& Indianapolis, p. 112-154 British Association of Aesthetic Plastic Surgeons Press Release 16 January 2006 'Over 22,000 surgical procedures in the UK in 2005' http://www.baaps.org.uk/ accessed July 20, 2006

Bronfen, E. (1992) Over Her Dead Body: Death, femininity and the aesthetic, Manchester University Press, Manchester 
Chernin, K. (1994) The Obsession: Reflections on the Tyranny of Slenderness, Harper Perennial, USA \& Canada

Covino, D. C. (2004) Amending the Abject Body: Aesthetic Makeovers in Medicine and Culture, State University of New York Press, Albany

Extreme Makeover official website (n.d.) http://abc.go.com/primetime/extrememakeover accessed 27 August 2005

Fraser, S. (2003) Cosmetic Surgery, Gender and Culture Palgrave Macmillan, London \& New York

Fuller, G. (1997) ‘Generation Airbag’ (exhibition review), Globe e Journal of Contemporary Art, Issue 5 http://www.arts.monash.edu.au/visarts/globe/issue5/sbtxt.html accessed 27 August 2005

Gilman, S. L. (1999) Making the Body Beautiful: A Cultural History of Aesthetic Surgery, Princeton University Press, Princeton, New Jersey Goodbyemag, (n.d.) 'Lolo Ferrari’ www.goodbyemag.com www.goodbyemag.com Greer, G. (2000) ‘Gluttons for Porn’, The Observer, Sunday September 24, http://observer.guardian.co.uk/review/story/0,6903,372210,00.html accessed July 20, 2006

Grimm Brothers (1973) 'Snow-White and the Seven Dwarfs', in The Juniper Tree and Other Tales from Grimm, 2, (Eds. Segal, L. \& Sendak, M) The Bodley Head, London, p. 256-274

Haiken, E. (1997) Venus Envy: a History of Cosmetic Surgery, The Johns Hopkins University Press, Baltimore, Maryland 
Henley, J. (2000) 'Larger than Life’, The Guardian Archive http://www.guardian.co.uk accessed July 20, 2006

------ (2002) ‘Husband arrested for Lolo Ferrari’s Murder’, The International Guardian, http://www.guardian.co.uk/international/story/0,3604,660564,00.html accessed July 20, 2006

------ (2002a) ‘Doing Lolo Justice’, Guardian Unlimited,

http://www.guardian.co.uk/elsewhere/journalist/story/0,7792,840235,00.htm July 20, 2006

Hesse-Biber, S. (1996) Am I Thin Enough Yet?: The Cult of Thinness and the Commercialization of Identity, Oxford University Press, Oxford \& New York

Heywood, L. (1998) Bodymakers: A Cultural Anatomy of Women's Body Building, Rutgers University Press, New Brunswick

Jacobson, N. (2000) Cleavage: Technology, Controversy, and the Ironies of the Manmade Breast, Rutgers University Press, New Brunswick, NJ MacDonald, M. (1999) 'The Dark Side of Humanity: The Work of Robert Hertz and Its Legacy’ (book review) The Australian Journal of Anthropology http://www.findarticles.com/p/articles/mi_m2472/is_1_10/ai_55007538 accessed 31 May 2012

Marianne (n.d.) YesThey’reFake www.yestheyrefake.net accessed 31 May 2012

Stratton, J. (1996) The Desirable Body: Cultural Fetishism and the Erotics of Consumption, Manchester University Press, Manchester \& New York

Tseëlon, E. (1995) The Masque of Femininity, The Presentation of Woman in Everyday Life, Sage Publications, London, Thousand Oaks, New Delhi 
Shabazz Steward, N. I'm Juxtaposing (web log)

http://www.8bm.com/diatribes/Volume01/diatribes016/diatribes313-

333/diatribes315.htm accessed July 20, 2006

Stewart, S. (1993) On Longing: Narratives of the Miniature, the Gigantic, the Souvenir, the Collection, Duke University Press, Durham \& London

Warner, M. (1994) 'Wicked Stepmothers: The Sleeping Beauty', From the Beast to the Blonde, Chatto \& Windus, London, p. 218-240

Young, I. M. (1992) 'Breasted Experience: The Look and the Feeling’ The Body in Medical Thought and Practice, (Ed. Leder, D.) Klewer Academic Publishers, Dordrecht, Boston, London, p. 215-230

Zimmerman, S. M. (1998) Silicone Survivors: Women's Experiences with Breast

Implants, Temple University Press, Philadelphia 